\title{
Pore properties controlling permeability prediction in carbonates
}

\author{
Roseane Missagia, Marco Ceia, Lorena Figueiredo, Irineu Lima Neto, UENF/LENEP
}

Copyright 2019, SBGf - Sociedade Brasileira de Geofísica

This paper was prepared for presentation during the $16^{\text {th }}$ International Congress of the Brazilian Geophysical Society held in Rio de Janeiro, Brazil, 19-22 August 2019.

Contents of this paper were reviewed by the Technical Committee of the $16^{\text {th }}$ International Congress of the Brazilian Geophysical Society and do not necessarily represent any position of the SBGf, its officers or members. Electronic reproduction or storage of any part of this paper for commercial purposes without the written consent of the Brazilian Geophysical Society is prohibited.

\section{Abstract}

Accurate permeability prediction is crucial in reservoir characterization as well in determining fluid flow in porous media, which may optimize the production of the field. Moreover, reservoir characterization associates knowledge textural and mineralogical of the rock characteristics, in addition to geometric properties of the porous space.

This work focuses on the analyses of the influence of pore structure parameters on absolute permeability employing the integrated experimental data analysis for providing empirical models that comprise those properties. The results indicated a link between pore properties to predict the absolute permeability through multiple linear regression (MLR) methodology.

\section{Introduction}

Carbonate rocks exhibit complex petrophysical behavior related to their complex pore geometry and a broad range of pore size distribution. Therefore, the characterization of petrophysical properties of carbonate rocks remains challenging, since there are not universally applicable to petrophysical relationships. Porosity and pore size distributions (PSD) are indispensable proprieties, required to assess reservoir volume and evaluate the producibility, permeability prediction, and elastic property estimative (Saidian et al., 2014). Methods to measure these properties demand to capture an ample variation in pore sizes and shapes. It justifies the quantification of pore space with visual (DIA - 2D thin section and $3 D \mu C T$ image; SEM - Scanning Electron Microscopy) and nonvisual techniques (N2 - Nitrogen Gas Adsorption, MIP, Helium Expansion, and Nuclear Magnetic Resonance (NMR)).

In this study, we achieved an integrated analysis connecting MPI and 2D DIA to assess pore attributes of carbonates on core plugs and thin section scales. The intention of this experimental work was analyzing the influence of depositional textures and pore attributes on MPI responses to permeability prediction, employing convention statistical technique - Multiple Linear Regression (MLR).

\section{Materials and Method}

The dataset includes eight carbonate samples extracted from different USA outcrops: Edward Plateau (Edward Yellow - EYI/EYII; Edward White - EW, Desert Pink -
DPI/DPII); Thornton (Silurian Dolomite - SD); Wisconsin (Wisconsin - W); Bedford (Indiana limestone - IL).

Table 1 lists the mineral composition obtained from X-Ray Diffraction (XRD), Rietveld approach and X-Ray fluorescence (XRF), to the textural classification of the specimens.

Figure 1 exhibits thin sections utilized in the petrographic characterization of the pore texture and 2D DIA for obtaining geometric parameters, such as perimeter over an area (POA) and dominant pore size (DPS).

Table 1 - Core samples and their physical characteristics

\begin{tabular}{|c|c|c|c|}
\hline Rock & Mineral (\%) & Texture & Formation \\
\hline Edward Yellow 1 & \multirow{2}{*}{$\begin{array}{l}\text { Calcite } 99.7 \% \\
\text { Quartz } 0.3 \%\end{array}$} & \multirow[t]{2}{*}{ Packstone } & \multirow[t]{6}{*}{ Edwards } \\
\hline Edward Yellow 2 & & & \\
\hline Desert Pink1 & \multirow{2}{*}{$\begin{array}{l}\text { Calcite } 99.8 \% \\
\text { Quartz } 0.2 \%\end{array}$} & \multirow[t]{2}{*}{ Crystalline } & \\
\hline Desert Pink 2 & & & \\
\hline Edward White & $\begin{array}{l}\text { Calcite } 99.63 \% \\
\text { Quartz } 0.37 \%\end{array}$ & $\begin{array}{l}\text { Cemented } \\
\text { Grainstone/ } \\
\text { Packstone }\end{array}$ & \\
\hline Austin Chalck & $\begin{array}{l}\text { Calcite } 99.90 \% \\
\text { Quartz } 0.09 \%\end{array}$ & $\begin{array}{l}\text { Cemented } \\
\text { Grainstone }\end{array}$ & \\
\hline Silurian Dolomite & Dolomite $100 \%$ & Crystalline & Thornton \\
\hline Indiana Limestone & $\begin{array}{l}\text { Calcite } 99.85 \% \\
\text { Quartz } 0.16 \%\end{array}$ & $\begin{array}{l}\text { Cemented } \\
\text { bioclastic } \\
\text { grainstone }\end{array}$ & Bedford \\
\hline Wisconsin & $\begin{array}{l}\text { Dolomite } 83.3 \% \\
\text { Quartz } 16.3 \% \\
\text { Calcite } 0.7 \%\end{array}$ & Crystalline & Wisconsin \\
\hline
\end{tabular}

Figure 1 displays thin sections of rocks EY I/II, EW, W, $\mathrm{DPI}$, and SD. These samples are mostly composed of the mineral calcite, except $\mathrm{SD}$ and $\mathrm{W}$ samples formed by more than $83 \%$ of dolomite.

In these thin sections, according to Duhan classification:

- EY(I/II) - grainstone cemented, with cementation of calcitic origin already recrystallized and texture similar to that of the grain;

- EW - bioclastic grainstone or packstone, predominating the moldic porosity;

- W - crystalline carbonate that underwent diagenetic processes, caused by effects of temperature and pressure;

- DP I - crystalline carbonate that presents calcite in high crystallization state, with the presence of micrites and micropores inside the micrite, and predominant cellular porosity;

- SD - dolomite characterized by intercrystalline porosity. 


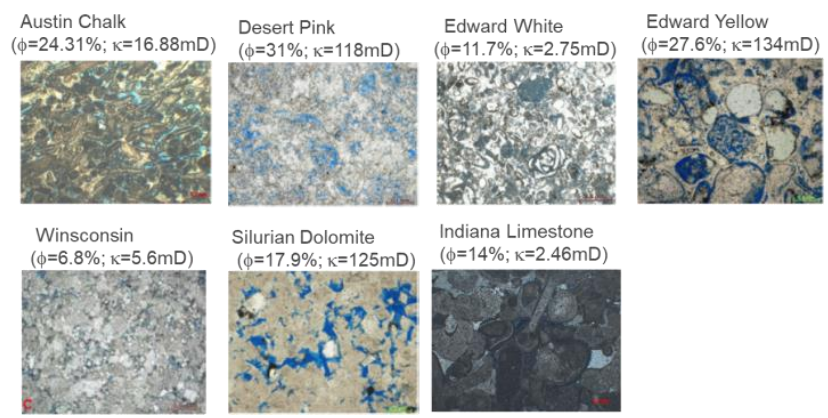

Figure 1 - Illustrate the interdependence between pore throat radius and grain selection from rock's thin sections

Figure 2 displays the workflow implemented to permeability prediction from textural, mineralogical and pore structure characterization in carbonate core samples.

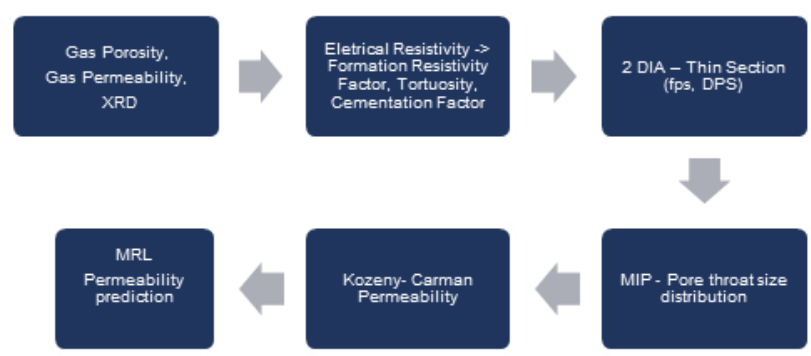

Figure 2 - Workflow to predict permeability

Porosity $(\phi)$ measurements at laboratory conditions were obtained by the helium gas expansion technique (API, 1988), while gas permeability $\left(\mathrm{K}_{\mathrm{He}}\right)$ using a PERG 200 Permeameter, operating at a pressure of 2000 psi.

Mercury Intrusion Porosimetry (MIP) was determined through Autopore IV 9520 from Micromeritics, operating with a pressure limit of 66,000 psi, Figure 3 .

Even though, some pore-sizes and shapes may be measured visually from 2D DIA, MIP has been indicated for characterizing pore features, pore throat size distributions in porous media from a micro-macro scale.

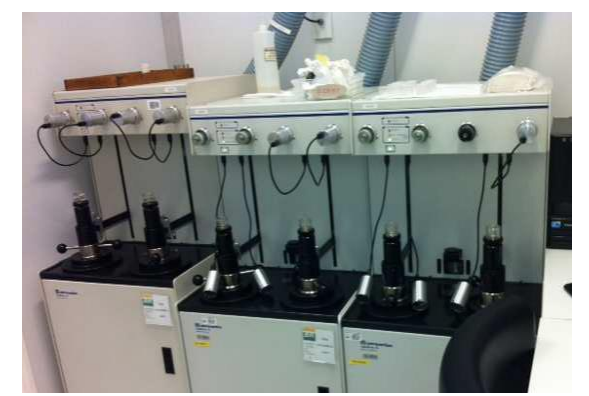

Figure 3 - Autopore IV 9520 from Micromeritics operating with a pressure limit of $66,000 \mathrm{psi}$

The Washburn equation provides a relationship between applied pressure and pore throat size (Leon, 1998), (Equation 1).
$D=-\frac{4 \sigma \cos \theta}{P}$

where $\sigma$ is the superficial mercury tension, $D$ the corresponding pore throat size, and $\theta$ the contact angle between the sample and the mercury, and $P$ the applied pressure.

The electrical resistivity of brine-saturated samples was acquired by Fluke Resistivimetry RCL PM6306 system to estimate by Archie equations the formation resistivity factor (FRF), tortuosity ( $\mathrm{T})$ and cementation factor $(\mathrm{m})$, Equations 2 and 3 . The solution used to saturate samples had a concentration of $0.23 \mathrm{~mol} / \mathrm{L}$ (13455 ppm) of $\mathrm{NaCl}$.

$F R F=\frac{R o}{R w}$

$$
F R F=\phi^{-m}
$$

here, $m$ represents the slope of the linear trend of FRF $x$ $\phi$. Archie (1942) stated that $m$ vary according to the degree of cementation of the rock. The tortuosity $(\mathrm{T})$ was defined as the ratio of the actual length of a flow path to the sample length, and it ranges according to the pore geometry, $\Phi$ and FRF, (Equation 4), (Azar, 2008).

$$
\mathrm{FRF} * \phi=\tau
$$

Equation 5 illustrates the Kozeny-Carman modified equation allowed to estimate the permeability using the distribution of pores throat size from MIP to evaluate $\phi$ occurrence, emphasizing the individual contribution of pore volume to the permeability. The geometric parameters $\left(S_{\text {gvr }}\right.$ and $\left.\mathrm{fps}\right)$ were obtained by 2D DIA, according to Weger, (2009).

$\mathrm{k}_{\mathrm{KC}}=\frac{\phi^{3}}{(1-\phi)^{2}}\left[\frac{1}{\mathrm{fps} \tau \mathrm{S}_{\mathrm{gvr}}^{2}}\right]$.

Pore size distribution (PSD) is determined from mercury intrusion into pores as a function of the applied pressure, Equation 1.

The volume of mercury penetration for each pressure is the difference between the respective cumulative intrusion volumes, as pressure increase, mercury penetrates the small pore throat.

In this study, we used Ahr (2005) to classify the pore size system determined by MIP into micropores $(<0.5 \mu \mathrm{m})$, mesopores $(0.5-5 \mu \mathrm{m})$, and macropores $(>5 \mu \mathrm{m})$.

Dominant Pore Size (DPS) indicates the pore-size range that dominates the sample. In the dataset, this parameter varied between $3.83-40.14 \mu \mathrm{m}$.

\section{Results}

Figure 1 shows the types of pores present in each sample studied. According to the classification of Ahr (2008) it is possible to visualize the specific porous structure composed of meso-macroporosity (申meso-macro) and microporosity $\left(\phi_{\text {micro }}\right)$. It is important to highlight that $\mathrm{k}_{\mathrm{KC}}$ 
was estimated as a function of $\mathrm{S}_{\mathrm{vgr}}, \tau, \mathrm{f}_{\mathrm{ps}}$ and $\phi$ (Equation 5).

Perceive that the samples DP I/II and EY I/II, report less than $10 \%$ of the porous system composed by microporous, while other samples exhibit more occurrence of micropore (Figure 2). In these experiments, the maximum pressure achieved by the MIP equipment limited the measurement of the smallest pore size.

Figure 3 displays the pore throat radius distribution versus porous volume fraction, highlighting that although the samples exhibit an expressive micropores occurrence, the most substantial pore volume fractions are associated with the meso-macropores.

Figure 4 shows that samples with greatest t value, micritic pores and diagenetic processes evidenced retention of mercury between the intrusion and extrusion curves.

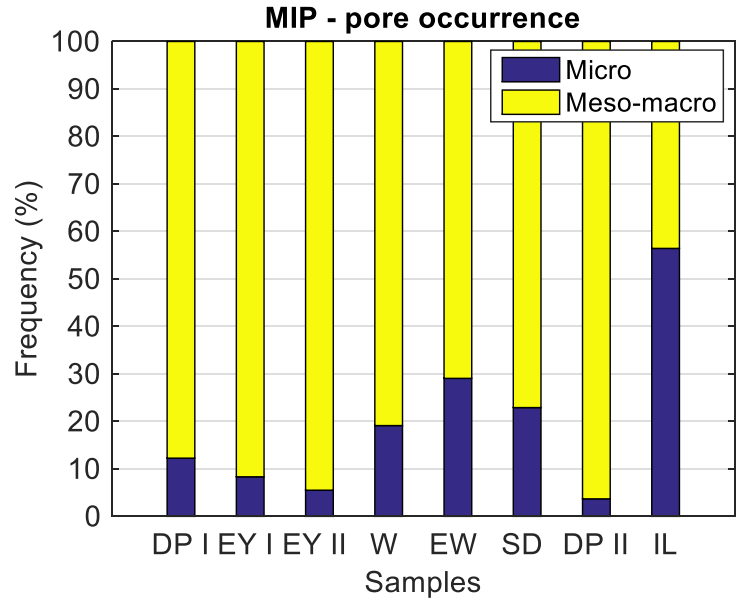

Figure 2 - The porous scale followed Ahr (2008) classification

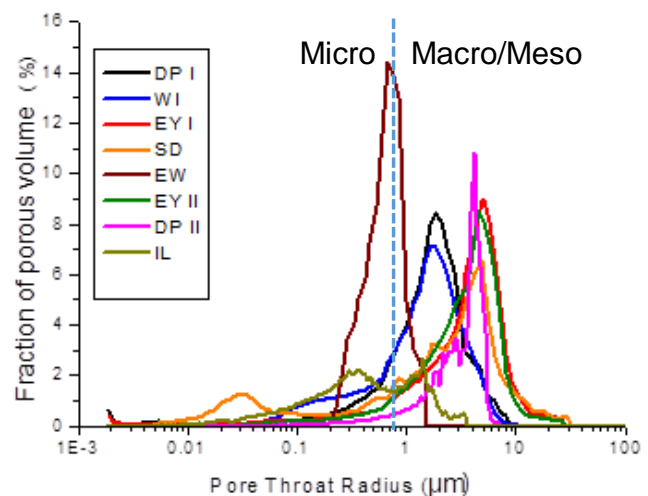

Figure 3 - The pore throat radius $(\mu \mathrm{m})$ in function of porous volume fraction $(\%)$, showing the pore size distribution and pore system characteristics of each specimen

In opposition, its visible in the thin section (Figure 1) that DP sample, despite having a low value of $\tau$, also displays retention of mercury inside pores; probably caused by the advanced recrystallization process, with the presence of micrite porosity $\left(\phi_{\text {micrite }}\right)$ within the micrite matrix.

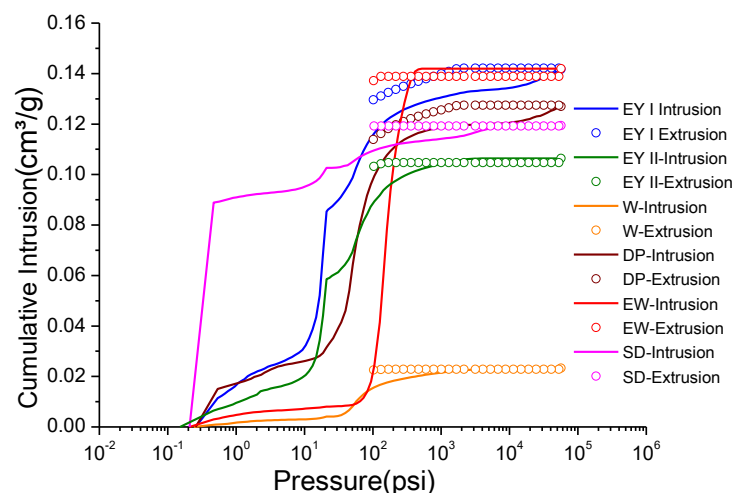

Figure 4 - Mercury intrusion and extrusion data in a set of carbonate rocks.

Figure 5 shows the correlation coefficient of the $\mathrm{k}_{\mathrm{He}}$ with $\phi_{\mathrm{He}}$ is $\mathrm{R}^{2}=0.695$, while the correlation with only the fractions $\phi_{\text {meso-macro }}$ and $\phi_{\text {micro }}$ is $R^{2}=0.743$ and $R_{2}=0.196$, respectively. Even with such correlation coefficient, IL, SD and $\mathrm{W}$ samples are far away from the adjustment line, due to the crystalline texture. These samples show approximately more than $40 \%$ of $\phi$ micro, which is the case of the IL sample. The SD sample, although presenting $55 \%$ of pmicro and having $45 \%$ of $\varphi$ mesomarco is also a spurious point of the adjustment line, which may be justified by the higher $\tau$ value.
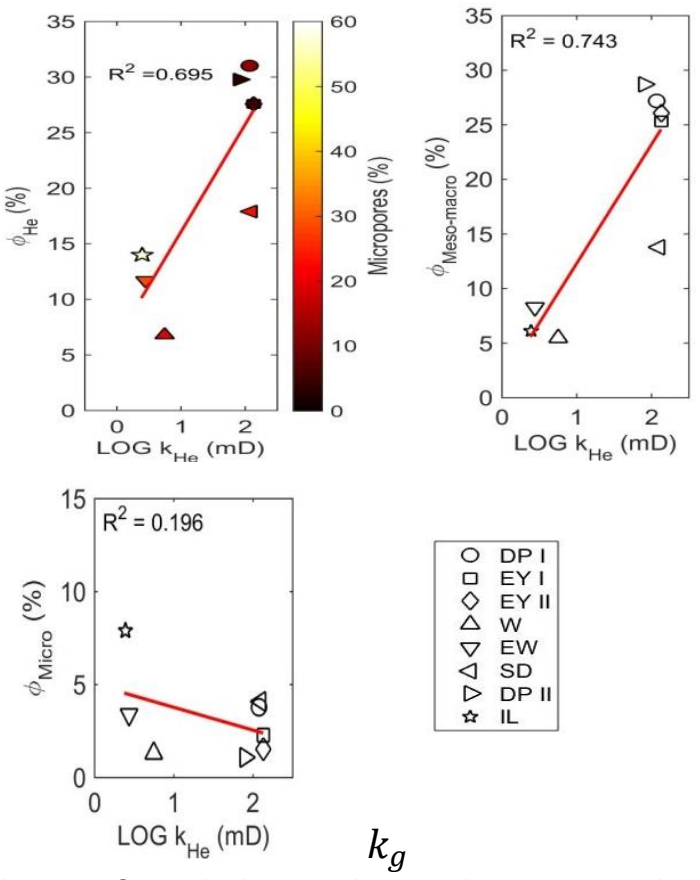

Figure 5 - Croosplot between $\mathrm{k}_{\mathrm{He}} \times \phi_{\mathrm{He}} ; \mathrm{k}_{\mathrm{He}} \times \phi_{\text {meso/macro }} ; \mathrm{k}_{\mathrm{He}} \times \phi_{\text {micro }}$. The SD and $W$ samples are spurious points, due to the crystalline texture. These samples show high $\phi_{\text {micro }}$ content and high $\tau$ value and diagenetic processes

The estimation of $k_{k c}$ requires using $\tau$ and $f_{p s}$; therefore, due to experimental limitations, only DP I, EY I/II, EW, W, and SD samples could be evaluated.

Figure 6 (Top) shows the correlation of $\mathrm{k}_{\mathrm{KC}} \times \mathrm{k}_{\mathrm{He}}$ considering the $\phi_{\text {meso-macro }}$ fraction; (Bottom) displays $k_{k c} X$ 
$\mathrm{k}_{\mathrm{He}}$ and the $\phi_{\text {micro }}$ fraction, presenting $\mathrm{R}^{2}=0.81$, e $R^{2}=0.0$, respectively. Despite the reduced number of samples, the quadratic adjustment increased, suggesting that the DP II sample taken from the fit exerted lower participation of $\phi_{\text {micro, }}$, while DPI, EY(I/II), SD, EW, and W expressed higher participation of $\phi_{\text {meso-macro. }}$.
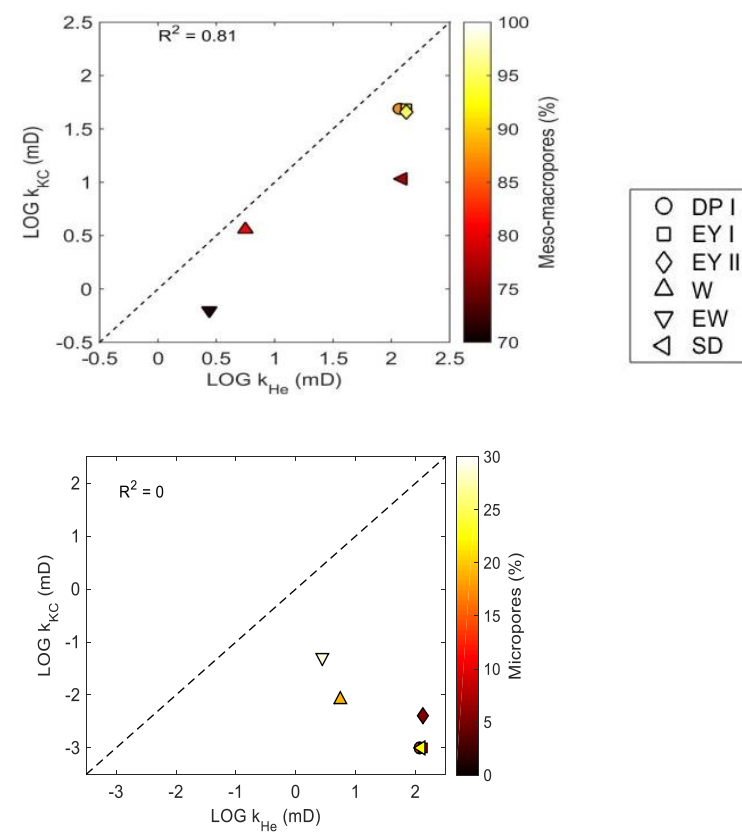

Figure 6 - shows the correlation of $\mathrm{k}_{\mathrm{KC}} \times \mathrm{k}_{\mathrm{He}}$ take considering the

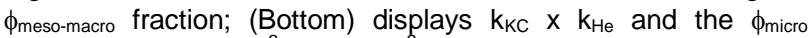
fraction, presenting $R^{2}=0.81$, e $R^{2}=0.0$, respectively.

Once the correlations between $\mathrm{k}_{\mathrm{He}}, \mathrm{k}_{\mathrm{KC}}$ and $\phi_{\text {meso-macro }}$ displayed proper adjustments $\left(R^{2}=0.81\right.$; Figure 6 (top)), it was performed a sensibility analysis through simple and multivariate linear regression of $\mathrm{k}_{\mathrm{He}} \mathrm{X}$, $\phi_{\text {meso-macro, }} \tau$, $\mathrm{m}$, and DPS.

Table 2 summarizes the results of the linear regression that allowed establish the link between $\mathrm{k}_{\mathrm{He}}, \phi_{\mathrm{m}}$ and geometric parameters. The parameter that most influenced this analysis was $\tau$ with $R^{2}=0.76$, then $\mathrm{k}_{\mathrm{He}}$ and

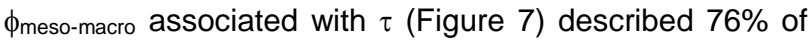
$\mathrm{k}_{\mathrm{He}}$ through the MLR.

The addition, the global parameters $\mathrm{m}$, DPS and $\tau$ did not interfere in the analysis of $\mathrm{k}_{\mathrm{He}} \mathrm{x}$ कmeso-macro, while DPS improved the fit from $R^{2}=0.64$ to $R^{2}=0.71, \tau$ could increase the $R^{2}=0.76$.

The values of $p$-value $(<0.05)$ and Statistical power $(>0.8)$ are within the range expected for analysis of $\mathrm{k}_{\mathrm{HE}} \mathrm{X}, \phi_{\text {meso- }}$ macro $X \tau$, showing a low probability that these errors were committed in Multivariate linear regression (MLR), according to Brooks and Barcikowski, (2012).
Table 2 Summary of the MLR used for predicting permeability

\begin{tabular}{|c|c|c|c|c|}
\hline Method & Equation & $\mathrm{R}_{\text {ajusted }}^{\mathrm{R}^{2}}$ & $\begin{array}{l}T- \\
\text { Stat }\end{array}$ & $\begin{array}{l}P \text { - } \\
\text { value }\end{array}$ \\
\hline LR & $\log (k)=0.39+0.07 \phi_{\text {macro } / \text { meso }}$ & 0.64 & 3.23 & 0,03 \\
\hline \multirow[t]{3}{*}{ MLR } & $\begin{array}{l}\log (k)=-0.64+0.05 \phi_{\text {meso } / \text { macro }}+ \\
0.57 \mathrm{~m}\end{array}$ & 0.64 & 1.85 & 0.16 \\
\hline & $\begin{array}{l}\log (\mathrm{k})=-0.30+0.05 \\
\Phi_{\text {meso } / \text { macro }}+0.02 \text { DPS }\end{array}$ & 0.71 & 2.21 & 0.11 \\
\hline & $\begin{array}{l}\log (k)=-0.40+0.08 \phi \text { meso/macro }+ \\
0.074 \tau\end{array}$ & 0.76 & 4.03 & 0.03 \\
\hline
\end{tabular}

Figure 7 exhibits a simulation employing the relationship empirical obtained for the carbonates in which was performed with the inclusion of the 03 samples with similar textures of the dataset used to propose such permeability prediction empirical equations.

In this same figure, $R^{2}$ fitted shows the difference between the $\mathrm{k}_{\mathrm{He}}$ and $\mathrm{k}_{\text {predicted, }}$ and expresses the importance of the $\phi_{\text {micro }}$ and $\tau$ controlling the permeability.

$$
\mathrm{R}_{\text {Fitted }}^{2}=\frac{\left(k_{H e}-k_{\text {pred }}\right) 2}{k_{H e}}
$$
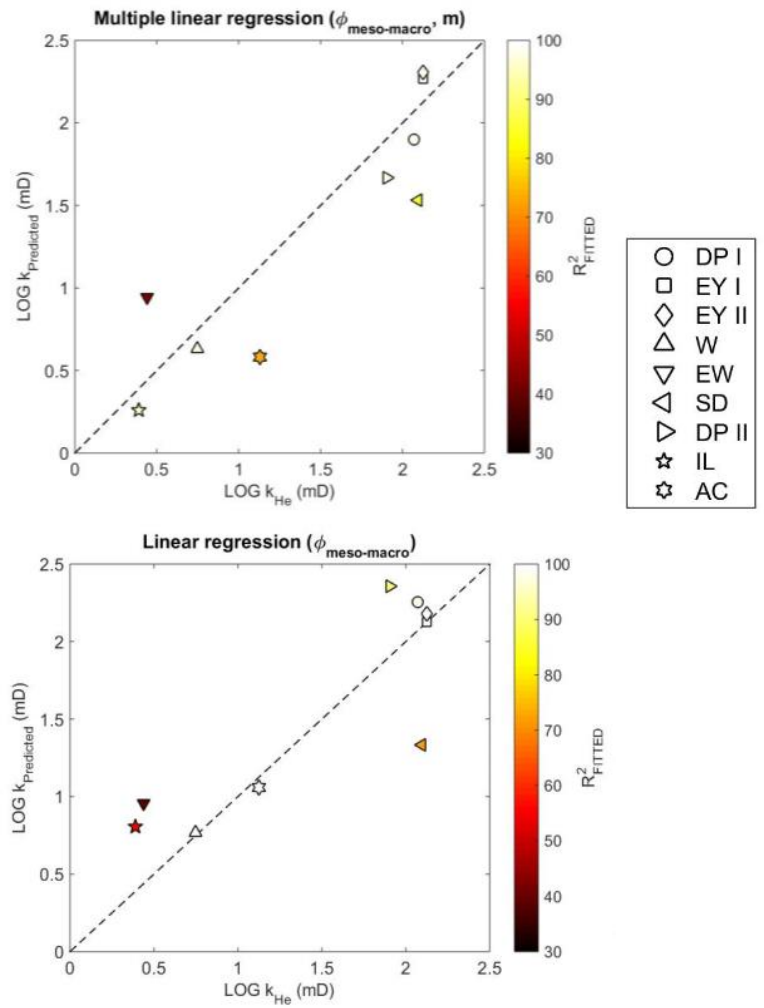

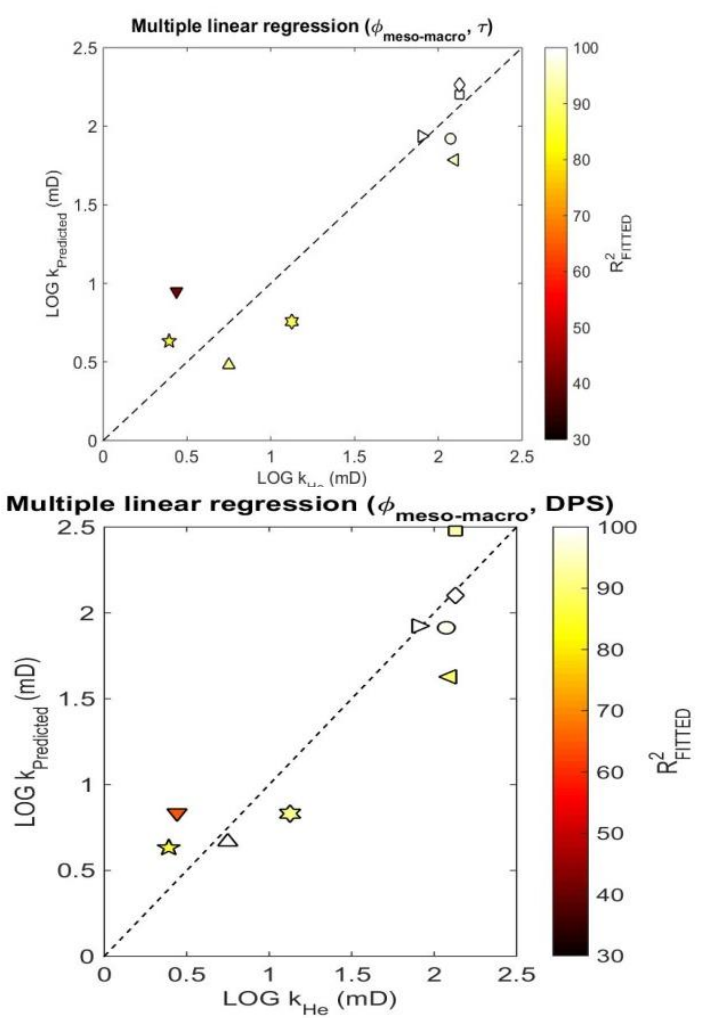

Figure 7 - Crossplots between $\mathrm{k}_{\mathrm{He}} \times \mathrm{k}_{\text {predicted }}$ illustrates a test using the empirical relationships obtained for the carbonates, according to Table 2

\section{Conclusions}

In this work, we examined the relationship between permeability, porosity and pore attributes in a set of carbonate samples.

Permeability prediction based only on linear dependence on porosity may not produce accurate results in those type of rocks, notably when are present different textures in the dataset.

The addition of pore attributes as tortuosity may improve the accuracy of the permeability prediction, mainly of the limestones and dolomites textures that may exhibit great meso-macro porous content.

Despite a reasonable adjustment between permeability prediction and experimental permeability, these measurements appear to exhibit dispersion values associated with an unusual percentage of micropores as consequence of mineral dissolution caused by diagenetic processes.

A combination of porosity (macro-meso) and tortuosity could describe $75 \%$ of the experimental permeability, demonstrating its efficacy as controlling factors of the permeability.

\section{Acknowledgments}

This study was financed in part by the Coordenação de Aperfeiçoamento de Pessoal de Nível Superior - Brasil (CAPES) - Finance Code 001. Authors also thank UENF/LENEP, PRH-226/PETROBRAS for all environment and structure provided to the execution of this work. RM and MC also thank CNPq for Technological Development and Innovation grant - DT II.

\section{References}

Archie, G.E., 1942. The electrical resistivity log as an aid in determining some reservoir characteristics. Trans. AIME 146, 54-62.

Ahr, W. Geology of Carbonate Reservoirs: The Identification, Description, and Characterization of Hydrocarbon Reservoirs in Carbonate Rocks, Nova York: John Wiley \& Sons Inc., 296 p., 2008.

Azar, J. (2008). An approach to defining tortuosity and cementation factor in carbonate reservoir rocks. 60 (2), pp. v.60, n.2, p.125-131.

Brooks, G. P.; Barcikowski, R. S. (2012). The PEAR Method for Sample Sizes in Multiple Linear Regression, Multiple Linear Regression Viewpoints, v. 38, p. 1-16.

Dunham, Robert J. Classification of carbonate rocks according to depositional textures. 1962.

Leon, C. (1998). New perspective in mercury porosimetry. Advances in Colloid and Interface Science, 76-77, 341372.

Saidian, M., Kuila, U., Rivera, S., Godinez, L. J., \& Prasad, M. (2014). Porosity and Pore Size Distribution in Mudrocks: A Comparative Study for Haynesville, Niobrara, Monterey and Eastern European Silurian Formations. Unconventional Resources Technology Conference.

Weger, Ralf J. et al. Quantification of pore structure and its effect on sonic velocity and permeability in carbonates. AAPG bulletin, v. 93, n. 10, p. 1297-1317, 2009. 